\title{
Funciones de Gobierno de la Audiencia de Canarias y normas de Derecho administrativo de la primera mitad del siglo XVI
}

La historia de nuestras instituciones en un período tan interesante como lo es el que abarca la Baja Edad Media y la Edad Moderna ha merecido hasta ahora escasa atención por parte de los especializados en estos estudios, si se exceptúa la de su trasplanté a las Indias, del que resaltan los óptimos frutos que alli produjeran. Pero cuando pretendemos realizar un análisis comparativo de su desarrollo simultáneo en los distintos territorios que abarcó la Corona de Castilla, nos hallamos faltos de uno de los términos, precisamente del originario. $\mathrm{Y}$ esto le ocurre al autor de estas líneas al intentar un estudio de la labor de gobierno que le cupo realizar a la Real Audiencia de Canarias: sabemos que las Chancillerias y Audiencias deI territorio peninsular español, aparte sus atribuciones como tribunal de apelación en el orden jurisdiccional, sirvieron a la vez de consejo consultivo en materia política de los gobernadores de los antiguos reinos y provincias (1), pero cuál fuese su extensión y si realizaron otras actividades de esta indole realmente no podemos precisarlo, aun cuando su desconocimiento

(1) G. Desdevises Du Dèzert, L'Espagne de l'Ancien Régime-Les Institutions. París,. 1899, pág. 138. R. Riaza y A. Garcfa Gallo, Manual de Historiol del Derecho Español. Madrid, 1935, pág. 548. 
frente a la patente labor de las Audiencias en las Indias en este orden de cosas, nos induzca a aceptar una clara diferencia a tal réspecto.

Esta falta de atención de nuestros historiadores del Derecho, explica que autores tan destacados en tales estudios como los profesores Riaza y García Gallo y el ilustre Magistrado del Tribunal Supremo don Pío Ballesteros no hayan conocido la fecha de fundación de la Audiencia de Canarias. Los dos primeros dan la de 1568, año citado antes igualmente por Desdevises du Dèzert, y el señor Ballesteros se limita a afirmar que ya funcionaba en el 1553 y que su residencia se fijó en la: isla de Gran Canaria por Real Cédula de 1566 (2).

La historia de este tribunal, aparte de las noticias que dan los cronistas locales, destacando entre ellos al fino prosista don José de Viera y Clavijo (3), fué trazada en un interesante librito publicado en Madrid el año 1815 por el que fué por muchos años su fiscal don José María de Zuaznávar y Francia, con el título de Noticias histórico-legales de la Real Audienicia de Canarias, desde la conquista de aquellas islas hasta el año 1755, que unida a otra obra del mismo autor; impresa también en la capital del Reino al siguiente año 1816, que denominó Ilustración apologética de un Real Decreto expedido por el señor Rey Don Felipe $V$ para las islas Camarias en 10 de febrero de 1791 (4), proporcionan valiosos datos para conocer la labor que le cupo desarrollar. Pero no son éstas las únicas fuentes para su estudio. Es preciso analizar también unas muy interesantes Ordenanzas que le fueron dadas en 1531, recientemente salidas a la luz (5); las cartas y cédulas reales (6) expe-

(2) Riazn, García Gallo y Desdevses du Dèzert, $O p$. cit., y P. Ballesteros, La función política de las Reales Chancillerias Coloniales, en aRevista de Estudios Politicos», año VI, núms. 27-28. Madrid, 1946.

(3) J. DE Viera y Clavijo, Noticias de la Historia General de las Islas Canarias, tomo III.

(4) Ambas obras impresas en la imprenta que fué de Fuentenebro, calle de Jacometrezo y reimpresas en Santa Cruz de Tenerife, Imprenta Isleña, 1864.

(5) Libro Rojo dc Gran Canaria, ediciones del Excmo. Ayuntamiento de Las - Palmas de Gran Canaria, II. Las Palmas de Gran Canaria, 1947, con introducción y notas de P. Gullen del Castillo, pág. LIV y 103-113.

(6) Si bien el término Real Cédula se suele usar genéricamente para indicar 
didas para regular su organización y funcionamiento, muchas de las cuales se insertaron en la Nueva y en la Novísima Recopilación, y, muy principalmente, las resoluciones de este Tribunal, pues en cuantos casos lo que las instituciones fueron no puede conocerse por las normas legales que las crearan o regulasen, es ineludible saber cómo actuaron en contacto con las realidades de cada momento histórico.

Y esta es la labor en que el autor de estas líneas está empeñado. Si recogemos las noticias de Zuaznávar, veremos cómo a lo largo del siglo xvi no limitó sus actividades la Audiencia de Canarias a juzgar y sentenciar en materia civil o criminal ; sus Regentes y Oidores se preocuparon del abasto del Archipiélago, de combatir las plagas y epidemias que lo asolaron, de atender a su defensa contra los enemigos de la Corona, y si más tarde esta última función es asumida por un Capitán General -Gobernador-, Presidente de dicho tribunal, continúan -a cargo de éste importantísimas funciones de tutela sobre las Corporaciones insulares, y de gobierno y administración de todas las islas. En un Compendio de la historia de las Canarias, debida igualmente a la pluma del que fué su ya citado fiscal, el autor dice: "La Audiencia ha repartido muchos terrenos para ocupar las muchas manos ociosas que, por no perecer de hambre, deseaban salirse del pais; ha trabajado sobre el establecimiento de nuevas poblaciones, ha creado alcaldías y ayuntamientos para la más pronta y más fácil administración de justicia y para mejorar el gobierno de las antiguas; ha fomentado las escuelas de primeras letras ya existentes y formado otras donde no las había; ha procurado la conservación de los montes, el aumento y libertad de la agricultura, industria y comercio; ha socorrido las necesidades públicas en tiempo de langosta, volcanes, terremotos..."

tanto las cartas como las cédulas reales, hemos observado, por lo que a la época de los Reyes Católicos se refiere, una clara distinción entre unas y otras: las cartas reales eran más solemnes, encabezándose con los nombres de los monarcas y todos sus títulos; •en cambio, las cédulas sólo decían: eEl Rey Fulano de tal, nuestro... .

(7) Zuaznávar, Compendio de la historia de las Cairarias, formado en su principio con la concesión correspondiente para las escuelas de primeras letras de 
Si a estas actividades unimos otras que tuvo atribuídas, como las de inspección de bienes de propios municipales, la de los pósitos y alhóndigas; la misma que llama la atención al señor Ballesteros, o sea, que su Gobernador-Presidente asiste a las vistas, pero sin voto en los fallos y que cuando había de resolver asuntos judiciales de su exclusiva competencia entre gentes de guerra o en sus visitas a los lugares de la isla, había de asesorarse de un Letrado; y aquella contenida en el Real Decreto de Felipe $V$ de 10 de febrero de 1731 que atribuye a la Audiencia, como tribunal delegado del Consejo de Guerra, el conocimiento de todas las causas civiles y criminales de los aforados: todas ellas configuraron a este tribunal de características especiales y distintas a los del territorio peninsular español, más cercanas a las de las Audiencias indianas, cuyas amplias atribuciones en materia de gobierno conocemos por los trabajos de Ballesteros, Ruiz Guiñazú, Ots, Pelsmaeker, Haring, Cunningham y de tantos otros, pero con las que tampopo cabe identificarlo, pues los problemas del territorio en que le cupo actuar eran totalmente distintos a los que se plantearon en las Indias.

Estas circunstancias que se producen en el Tribunal de apelación de Canarias, desde su creación hasta que a principios del siglo xix las funciones de gobierno y tutela sobre las Corporaciones locales de las islas pasan a manos de los Jefes políticos y de la Diputación provincial, dan un destacado interés a su conocimiento detallado, pero trabajo de tal índole, que viene preparando el autor de estas líneas, excede de las posibilidades de un artículo de revista, por lo que ha debido aquí limitarse a enunciarlo a grandes rasgos, deteniéndose solamente en unas normas que a dicha Audiencia le fueron dadas a poco de su creación; cuya trascendencia excede del análisis de sus peculiaridades.

Antes de entrar en su estudio ha de precisarse el momento

aquellas islas, y hoy ilustrado y aumentado notablemente en obsequio de la verdad. Madrid, en la imprenta que fué de Fuentenebro, 1816. Reimpreso en Santa Cruz de Tenerife, imprenta Isleña, 1863 y recientemente en Las Palmas de Gran Canaria, por El Museo Canario. 
de creación de esta Audiencia. Por carta real del Emperador. y su madre, fechada en Granada el 7 de diciembre de 1526, expedida, según se deduce de otros documentos coetáneos, a petición de las Islas, se establece un Tribunal de apelación, compuesto de tres jueces, con jurisdicción en todo el Archipiélago y residencia en la isla de Gran Canaria. Esta provisión real, citada por nuestros. clásicos diccionarios administrativos, ha sido publicada por varios de los historiadores locales (8). El 5 de junio siguiente es expedida en Valladolid nueva carta real, en la que se repiten casi textualmente los términos de la anterior (9), comenzando a funcionar la Audiencia en el mismo año de 1527 (10).

Pero las discrepancias entre los Oidores y el Gobernador y los Cabildos de las islas comienzan muy pronto, razón por la cual, el de Gran Canaria envía a su regidor Diego de Narváez a la Corte en queja de los Magistrados, y, para practicar información sobre lo ocurrido y resolver diferencias, los $\mathrm{Re}$ yes, por carta real fechada en Madrid. el 22 de diciembre de 1529, nombran visitador al Ldo. Francisco Ruiz Melgarejo, quien, luego de investigar lo ocurrido y adoptar las medidas pertinentes, dicta en la Ciudad Real de Las Palmas el 24 de febrero de 1531 las Ordenanzas que habian de llevar su nombre, por las que reglamenta la actuación del Tribunal y deslinda atribuciones, las que fueron mandadas guardar por $R$. C. de 1553, que dispone sean leídas públicamente el primer día de audiencia de cada año (11).

Estas llamadas Ordenanzas de Melgarejo recogen normas

(8) Está citada por los diccionarios Alcubilla y Seix. La publicó J. de Viera y Clavijo, op. cit., tomo IV, apéndice, tomándola, nos dice, del Libro de Cédulas y Provisiones de la Chancilleria de Granada, impreso en 1551 , que se conservaba en la Biblioteca de la Real Academia de la Historia. El historiador regional A. Millares Torres la reprodujo en su obra y en el antes citado Libro Rojo de Gran Canaria se inserta, pág. 77.

(9) Vid. Libro Rojo de Gran Canaria, Introducción, XLVIII.

(10) Los Oidores dirigieron con fecha 24 de septiembre de. 1527 carta al Cabildo de Tenerife dando cuenta de haber quedado constituida, la que fué presentada por el mensajero Juan de la Rośa en éste el 2 de noviembre siguiente.

(11) Nueva Recopilación, 1. 17, tít. 3, lib. 3. 
de ciertas Instrucciones dadas a.los Jueces de grado de Sevilla, al tiempo que su autor dicta otras originales a la vista de los problemas que había de resolver.

Entre las primeras interesa ahora destacar la siguiente:

"Otrosí ordenamos e mandamos que quando se interpusiere appellación ante vos los dichos Jueces mayormente en causas tocantes a la governación de la dicha ciudad y su tierra que antes mandéis sobreseer en la execución veáis los processos. e vos informéis de los que mandan y ordenan lo que les mueve a lo hazer e después de ser informados e oidas las partes proveed en ello lo que os pareciere justo aviendo siempre consideración al bien público especialmente en cosas de poco perjuizio."

De las originales del visitador, se destacan a este respecto las que vamos a transcribir:

"Otrosí, que si alguna persona se agraviare de la postura e precio que le fuere puesta por los diputados a los mantenimientos que oviere de vender, que la tal persona pueda appelar y quexar para ante la ciudad para que estando Justicia e Regimiento todos juntos en su cabildo lo remedien y provean, conforme al fuero de los Reyes Católicos que esta Isla tiene, que da la orden en las cosas de la governación della, y si la tal persona se agraviare del dicho precio de los mantenimientos que por la ciudad fuere puesto e moderado que en tal caso pueda appelar para ante los dichos Jueces de alzada, para que por ellos visto provean lo que les pareciere justo."

"Otrosí, que quando la ciudad, Justicia e Regimiento della, hicieren alguna ordenanza general a todo el común, o pregón, que en tal caso si alguna persona o personas particulares dixeren ser agraviados por la tal ordenanza o pregón, que en tal caso puedan appellar de la Justicia e Regimiento para ante los dichos Juezes de alzada en los tales casos y en los casos en el capítulo antes deste contenidos manden llamar a la Justicia e Regidores e dellos brevemente se informen porqué razones e causas se mueven a hazer lo susodicho e llana e brevemente provean lo justo les pareciere, por manera que no consientan 
que aya pleitos entre los vecinos desta ciudad y el Regimiento. della, ni den lugar a ello."

- Resalta de la iectura de las anteriores disposiciones una separación de materias hoy encuadràdas en el Derecho administrativo, apuntándose algunas de sus características diferenciales con el Derecho privado, como se observa en la primera de las transcritas al ordenar se tuviese en cuenta la primacía del "bien público" en asuntos de la "governación de la ciudad". Las. restantes constituyen todo un sistema de garantias de la relación jurídico-administrativa en orden a la esfera municipal, mediante recursos jerárquicos y contenciosos, totalmente dispares. a los entonces establecidos para las cuestiones civiles y criminales.

Nos causa extrañeza el hallar en tal periodo de la evolución de nuestro Derecho normas como las transcritas, pero es que realmente, insistimos, se ha prestado muy escasa atención a este momento histórico y a sus instituciones, en tantos aspectos quebradas en su evolución en el siglo xIx, y aun en el anterior, para seguir modelos extranjeros. $\mathrm{Y}$ por esta misma razón aun hoy buscamos en otros ordenamientos jurídicos lo que fué nuestro, pero que olvidamos. Así ocurre con el denominado en la actual terminología recurso contencioso-administrativo objetivo o de anulación, sin acordarnos de lo que ya Hevía Bolaños dijo, recogiendo preceptos vigentes cuando escribía: "No sólo la partea quien toca particularmente lo proveído por el Cavildo lo puede contradecir, sino también cualquiera del pueblo a quien toca generalmente como a uno de él, por lo que toca al bien común, aunque sean elecciones y otras cosas graves y es parte legítima para ello» (12). ¿No es este último caso el de la típica acción. popular?

Leopoldo de la Rosa y Olivera

Secretario de la Mancomunidad Provincial

Interinsular de Santa Cruz de Tenerife.

(12) J. de Hévia Bolanos, Cwria filipica, I, 1, 29. 